\title{
SBI0206965, a novel inhibitor of Ulk1, suppresses non-small cell lung cancer cell growth by modulating both autophagy and apoptosis pathways
}

\author{
FANG TANG ${ }^{1,2}$, PENGCHAO HU ${ }^{3}$, ZETIAN YANG ${ }^{4}, \mathrm{CHAO} \mathrm{XUE}^{4}, \mathrm{JUN} \mathrm{GONG}^{1,2}$, \\ SHAOXING SUN ${ }^{1,2}$, LIU SHI ${ }^{1,2}$, SHIMIN ZHANG ${ }^{1,2}$, ZHENZHEN LI $^{1,2}$, \\ CHUNXU YANG ${ }^{1,2}$, JUNHONG ZHANG ${ }^{1,2}$ and CONGHUA XIE ${ }^{1,2}$

\begin{abstract}
${ }^{1}$ Department of Radiation and Medical Oncology, Zhongnan Hospital of Wuhan University; ${ }^{2}$ Hubei Key Laboratory of Tumor Biological Behaviors, Zhongnan Hospital of Wuhan University; ${ }^{3}$ Department of Pathology and Pathophysiology, School of Basic Medical Sciences, Wuhan University; ${ }^{4}$ Department of Thoracic and Cardiovascular Surgery, Zhongnan Hospital of Wuhan University, Wuhan, Hubei 430071, P.R. China
\end{abstract}

Received November 12, 2016; Accepted May 2, 2017

DOI: $10.3892 /$ or.2017.5635

\begin{abstract}
Lung cancer is a major public health problem worldwide. Non-small cell lung cancer (NSCLC) accounts for $85 \%$ of lung cancer cases. Autophagy has recently sparked great interest, and it is thought to participate in a variety of diseases, including lung cancer. Uncoordinated (Unc) 51-like kinase 1 (Ulk1), a serine/threonine kinase, plays a central role in the autophagy pathway. However, the role of Ulk1 in NSCLC remains unclear. We report that NSCLC cell lines exhibited high expression of Ulk1 and that Ulk1 was negatively correlated with prognosis in lung cancer patients. Knockdown of Ulk1 or the inhibition of Ulk1 by the selective inhibitor SBI0206965, inhibited cell proliferation, induced cell apoptosis and enhanced the sensitivity of cisplatin against NSCLC cells. Moreover, we demonstrated that Ulk1 exerted oncogenic activity in NSCLC by modulating both autophagy and apoptosis pathways. Inhibition of autophagy by SBI0206965 sensitized NSCLC cells to cisplatin by inhibiting cisplatin induced cell-protective autophagy to promote apoptosis. Furthermore, SBI0206965 promoted apoptosis in NSCLC cells independent of autophagy, which was partly mediated by destabilization of Bcl2/Bclxl. In summary, our results show that inhibition of Ulk1 suppresses NSCLC cell growth and sensitizes NSCLC cells to cisplatin by modulating both autophagy and apoptosis pathways, and that Ulk1 might be a promising target for NSCLC treatment.
\end{abstract}

Correspondence to: Dr Conghua Xie, Department of Radiation and Medical Oncology, Zhongnan Hospital of Wuhan University, 169 Donghu Road, Wuhan, Hubei 430071, P.R. China

E-mail: chxie_65@whu.edu.cn

Key words: Ulk1, non-small cell lung cancer, SBI0206965, cisplatin, autophagy, Bcl2, Bclxl

\section{Introduction}

Lung cancer is the most frequently diagnosed cancer and the leading cause of cancer death, resulting in more than 1.5 million deaths worldwide in 2012 (1). The morbidity of lung cancer has continued to increase worldwide, especially in less developed countries, in part because of air pollution. Non-small cell lung cancer (NSCLC) accounts for almost $85 \%$ of all lung cancer cases. Despite significant progress in the diagnosis and treatment of NSCLC, the 5-year overall survival rate of patients with NSCLC remains very low (2). Cisplatin-based, two-drug combination chemotherapy has been recommended as the first-line treatment for NSCLC, but intrinsic and acquired cisplatin resistance limits its efficacy in lung cancer treatment. Thus, the identification of new therapeutic targets and new methods to enhance the sensitivity of cisplatin for NSCLC would be of great value.

Autophagy is a process of phagocytosis of unnecessary or dysfunctional components, fusion with lysosomes and degradation of the contents of the lysosomes to maintain cellular homeostasis (3). As one of the important mechanisms of essential material recycling, autophagy is thought to participate in a variety of diseases, including lung cancer (4). Many tumors survive via autophagy, which suggests that targeting autophagy may be a universal method for cancer therapy (5). Dysregulation of autophagy is often observed in lung cancer (6). Inhibition of autophagy sensitizes NSCLC cells to chemotherapy $(7,8)$. Kinase inhibitors have proven successful in the clinic. As the only conserved serine/threonine kinase in the autophagy cascade, uncoordinated (Unc) 51-like kinase 1 (Ulk1) is a very attractive cancer drug target (5). Ulk1 plays a key role in the initial stages of autophagy by forming a complex with autophagy-related 13 (ATG13) and RB1-inducible coiledcoil 1 (RB1CC1) $(9,10)$. Under nutrient-rich conditions, both Ulk1 and ATG12 are phosphorylated by target of rapamycin (TOR), which represses Ulk1 kinase activity and thus results in inhibition of autophagy. Conversely, upon nutrient deprivation, activated AMP-activated protein kinase (AMPK) activates 
Ulk1, which subsequently leads to initiation of autophagy (11). Pike et al showed that Ulk1 promotes cell survival of several cancers (12). Moreover, overexpression of Ulk1 has been shown to be negatively correlated with the prognosis of a variety of cancers, such as colorectal cancer, breast cancer, human nasopharyngeal carcinoma and esophageal squamous cell carcinoma (12-16). Egan et al reported that the compound SBI0206965, a highly selective kinase inhibitor of Ulk1 both in vitro and in vivo, suppresses Ulk1-mediated phosphorylation events in cells and prevents Ulk1-dependent cell survival by suppressing autophagy (5). However, the roles of Ulk1 and SBI0206965 in NSCLC are largely unknown.

We report that Ulk1 was upregulated in NSCLC cell lines and was negatively correlated with prognosis in NSCLC patients. Knockdown of Ulk1 inhibited cell growth and sensitized NSCLC cells to cisplatin. Inhibition of Ulk1 by SBI0206965 reduced the proliferation of NSCLC cells and induces cell apoptosis by inhibiting autophagy and destabilizing $\mathrm{Bcl} 2 / \mathrm{Bclxl}$. In summary, our results show that SBI0206965 suppresses NSCLC cell growth and sensitizes NSCLCL cells to cisplatin by modulating both autophagy and apoptosis pathways and that Ulk1 is a promising therapeutic target for NSCLC treatment.

\section{Materials and methods}

Cell culture. The NSCLC cell lines A549, H1299, H292, H460, and HCC827 and the normal human lung cell line BEAS-2B were obtained from the American Type Culture Collection (Manassas, VA, USA). The cell lines were grown in RPMI-1640 medium (HyClone, South Logan, VT, USA), supplemented with $10 \%$ (v/v) fetal bovine serum (Gibco, Grand Island, NY, USA) and $100 \mathrm{IU} / \mathrm{ml}$ penicillin and $100 \mu \mathrm{g} / \mathrm{ml}$ streptomycin (Beyotime Biotechnology, Shanghai, China). All of the cells were cultured at $37^{\circ} \mathrm{C}$ in a humidified incubator with $5 \% \mathrm{CO}_{2}$.

Reagents and antibodies. Cisplatin and Z-VAD-FMK were purchased from Selleck (Houston, TX, USA). SBI0206965 was obtained from DC Chemicals (Shanghai, China). The anti-Ulk1 (8054) and anti-LC3 (3868) antibodies were obtained from Cell Signaling Technology (Danvers, MA, USA). The antiBcl2 (12789-1-AP) and Bclxl (10783-1-AP) antibodies were purchased from Proteintech (Chicago, IL, USA). The anti-p62 (ab109012) antibody was purchased from Abcam (Cambridge, UK). The mouse anti- $\beta$-actin monoclonal antibody (AM1021B) was from Abgent (San Diego, CA, USA).

Cell proliferation and EdU incorporation assay. A total of $1 \times 10^{4}$ cells in $100 \mu \mathrm{l}$ of supplemented culture medium per well were cultured in 96-well plates overnight, followed by treatment with the indicated compounds in quintuplicate for $72 \mathrm{~h}$. Cell viability was assessed at $450 \mathrm{~nm}$ using a microplate reader (Bio-Rad, Hercules, CA, USA), $1 \mathrm{~h}$ after adding $10 \mu \mathrm{l}$ of CCK-8 reagent (Cell Counting Kit-8, Dojindo Molecular Technologies, Inc., Kumamoto, Japan) to each well. Cell proliferation was also assessed using a Cell-Light EdU DNA cell proliferation kit (RiboBio, Guangzhou, China), according to the manufacturer's instructions. All analyses were performed three times.
Colony formation assay. H460 and A549 cells were seeded at 800 or 500 cells per well in $2 \mathrm{ml}$ of medium in 6-well plates. The cells were treated as required the next day, and were allowed to grow for 10-14 days in the constant temperature and humidity incubator until colonies formed. The cells were then washed twice with PBS, stained with a solution of $0.5 \%$ crystal violet and $70 \%$ ethanol, washed with PBS twice and dried. Colonies with $>50$ cells were counted, and each assay was conducted in triplicate and three separate assays were performed.

Annexin V assay of cell apoptosis. Cells were cultured in sixwell plates to $70-80 \%$ confluence and were then treated with the indicated compounds. After exposure for 48 or $72 \mathrm{~h}$, the cells were harvested by trypsin, washed twice with PBS, resuspended in $400 \mu \mathrm{l}$ of Annexin-binding buffer, and stained with $5 \mu \mathrm{l}$ of Annexin V-PE (FITC) at room temperature in the dark for $15 \mathrm{~min}$ and with $10 \mu \mathrm{l}$ of 7-AAD (PI) for $5 \mathrm{~min}$ according to the manufacturer's instructions for the Annexin V-FITC Apoptosis assay kit (BestBio, Shanghai, China). Both apoptotic cells and live cells were detected by flow cytometry (BD Biosciences, San Jose, CA, USA).

Plasmids and transfection. The shRNA vector pLKO.1 and GFP-LC3 plasmids were obtained from Addgene, Inc. (Cambridge, MA, USA). pLKO.1 puro was a gift from Bob Weinberg (Addgene plasmid \#8453) (17). GFP-LC3 was a gift from Jayanta Debnath (Addgene plasmid \#22405) (18). Endogenous Ulk1 was knocked down using pLKO.1-shRNA-Ulk1-1 (Mission TRC shRNA TRCN0000000838) and pLKO.1-shRNA-Ulk1-2 (Mission TRC shRNA TRCN0000000839). The control shRNA sequence was CAACAAGATGAAGAGCACCAA. Cells were transfected with the indicated plasmids according to the manufacturer's instructions for TurboFect DNA transfection reagent (Thermo Fisher Scientific, Waltham, MA, USA).

Western blotting. Cells were lysed on ice with cell lysis buffer (Beyotime, Shanghai, China), and the protein concentrations were measured using the Pierce BCA Protein assay kit (Thermo Fisher Scientific). The samples were subjected to 10 or $12 \%$ SDS-PAGE with a power supply (Bio-Rad) and transferred to polyvinylidene fluoride membranes (Millipore, Bedford, MA, USA). The membranes were blocked in 5\% skimmed milk (Difco Laboratories, Detroit, MI, USA) in TBST for $1.5 \mathrm{~h}$ and then incubated with primary antibodies overnight at $4{ }^{\circ} \mathrm{C}$, followed by incubation with the corresponding horseradish peroxidase (HRP)-conjugated secondary antibody (Proteintech) for $1.5 \mathrm{~h}$. Finally, the bands were visualized with the ECL system (Beyotime) by exposure to X-ray film. Actin was used as a loading control. All experiments were performed three times.

Total RNA isolation, reverse transcription and quantitative real-time PCR ( $q R T-P C R)$. Total RNA from NSCLC cells was isolated using TRIzol reagent (Invitrogen, Carlsbad, CA, USA). The quantity of isolated RNA was measured by NanoPhotometer (Implen, Munich, Germany). First-strand cDNA was synthesized using SuperScript First-Strand Synthesis System for RT-PCR (Invitrogen) using $2.5 \mu \mathrm{g}$ of 


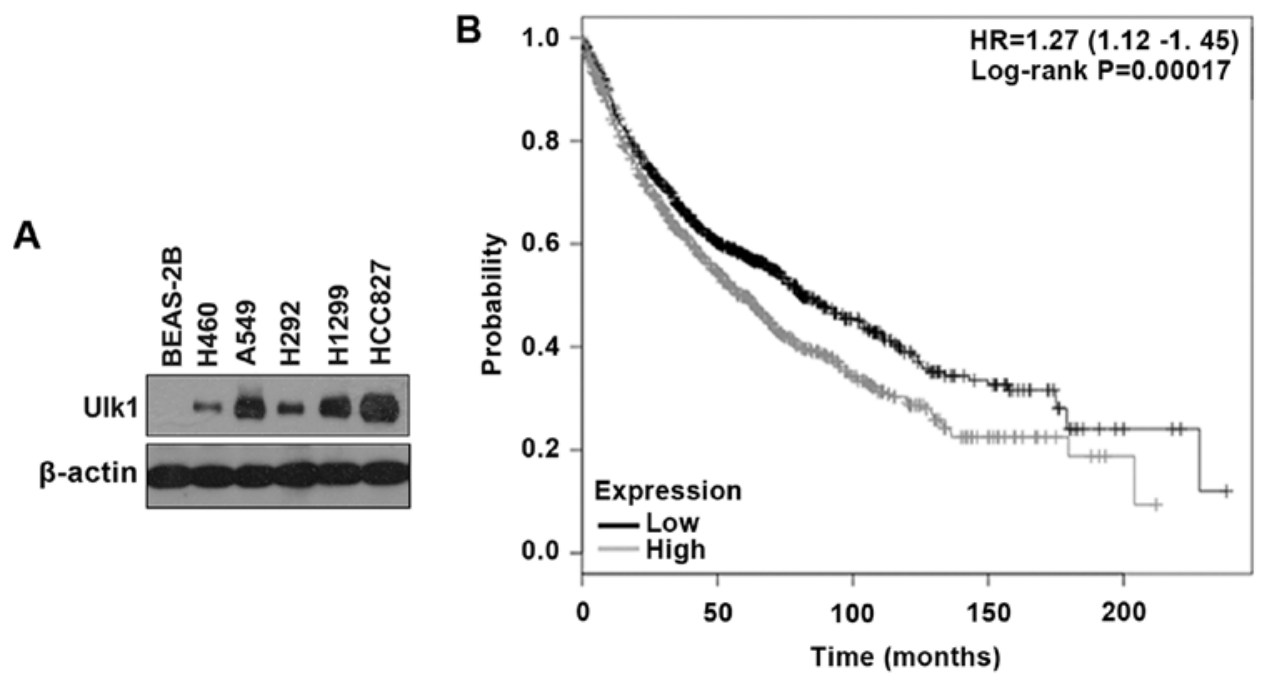

Figure 1. Ulk1 is upregulated in NSCLC cell lines and is negatively correlated with the prognosis of patients with NSCLC. (A) Ulk1 expression in five NSCLC cell lines and the normal human lung cell line BEAS-2B was determined by western blot analysis of whole lysates of the indicated cell lines. The results are representative data from three individual experiments. (B) The relationship between Ulk1 mRNA expression and the prognosis of patients with lung cancer was analyzed using the Kaplan-Meier plotter database (version 2015) (Kaplan-Meier plotter database website: http://kmplot.com/analysis/).

total RNA isolated from NSCLC cells. Each reaction of realtime polymerase chain reactions (PCR) was conducted with $\mathrm{SYBR}^{\circledR}$ Premix Ex Taq ${ }^{\mathrm{TM}}$ (Takara, Dalian, China) in a final volume of $20 \mu \mathrm{l}$ using $1 \mu \mathrm{g}$ of cDNA. $\beta$-actin was used as endogenous control transcripts for normalization of the target transcripts. All primers were tested for optimal annealing temperatures and PCR conditions were optimized with gradient PCRs on an iCycler (Bio-Rad). The PCR primer sequences for $\beta$-actin, $\mathrm{Bcl} 2$ and Bclxl are as follows (5' to 3', sense and antisense, respectively): Human $\beta$-actin sense: TGG CACCCAGCACAATGAA, and antisense: CTAAGTCATAG TCCGCCTAGAAGCA; humanUlk1 sense:GGCAAGTTCGA GTTCTCCCG, and antisense: CGACCTCCAAATCGTGCT TCT; human Bcl2 sense: GGTGGGGTCATGTGTGTGG, and antisense: CGGTTCAGGTACTCAGTCATCC; human Bclxl sense: GACTGAATCGGAGATGGAGACC, and antisense: GCAGTTCAAACTCGTCGCCT.

The PCR reaction was carried out as follows: step 1: $95^{\circ} \mathrm{C}$ $5 \mathrm{~min}$; step 2: 39 cycles at $95^{\circ} \mathrm{C}$ for $30 \mathrm{sec}, 60^{\circ} \mathrm{C}$ for $30 \mathrm{sec}$, $72^{\circ} \mathrm{C}$ for $30 \mathrm{sec}$; step $3: 95^{\circ} \mathrm{C}$ for $10 \mathrm{sec}, 65^{\circ} \mathrm{C}$ for $10 \mathrm{sec}$. Each reaction tube contained $10 \mu 12 \mathrm{X}$ SYBR Premix Ex Taq $+7 \mu 1$ nuclease-free water $+2 \mu \mathrm{l} 0.1 \mu \mathrm{g} / \mu \mathrm{l}$ primer (pair) $+1 \mu \mathrm{l}$ cDNA $(0.2 \mu \mathrm{g} / \mu \mathrm{l})$. Genes were amplified in triplicate. The average cycle threshold $(\mathrm{Ct})$ value for each group was determined and normalized by the endogenous control $\mathrm{Ct}$ value. Relative gene expression was analyzed using the $2-\Delta \Delta \mathrm{Ct}$ method.

Statistical analysis. Statistical software including SPSS 17.0 and GraphPad Prism 5.0 was used for data analysis. All values are presented as mean \pm standard deviation (SD) of triplicate measurements and repeated three times with similar results. All data were subjected to Student's t-test. Differences were considered statistically significant at $\mathrm{P}<0.05$.

\section{Results}

Ulk1 is overexpressed in NSCLC cell lines. It has been reported that in several cancers, such as breast cancer, colorectal cancer, esophageal squamous cell carcinoma and human nasopharyngeal carcinoma, Ulk1 is upregulated and is negatively correlated with prognosis, but the role of Ulk1 in NSCLC remains unclear (12-16). In the current study, the expression of Ulk1 was tested in five NSCLC cell lines (A549, H292, H460, H1299 and HCC827) and one normal human lung cell line (BEAS-2B). As shown in Fig. 1A, the NSCLC cell lines exhibited higher expression of Ulk1 compared with BEAS-2B cells. Moreover, by searching the online Kaplan-Meier plotter database for the analysis of the prognostic value of biomarkers using transcriptomic data in NSCLC (19), we found that high expression of Ulk1 is negatively correlated with prognosis in patients with lung cancer $(\mathrm{P}<0.01)$ (Fig. 1B). Tyrosine kinases inhibitors (TKIs) are considered as first-line treatment for advanced or metastatic NSCLC patients with epidermal growth factor receptor (EGFR) activating mutations in the clinic. HCC827 is an adenocarcinoma line with the E746-A750 EGFR deletion mutation and is sensitive to TKIs (20). In our preliminary experiment, we found that $\mathrm{HCC} 827$ cells showed striking growth inhibition with gefitinib treatment and that inhibition of Ulk1 did not increase the efficacy of gefitinib in HCC827 cells. Therefore, we used A549 and H460 cells in the following study instead of HCC827 cells, though HCC827 cells showed a higher expression of Ulk1 than the other cell lines (Fig. 1A).

Ulk1 promotes the proliferation of NSCLC cells. As Ulk1 is overexpressed in NSCLC, we speculated that Ulk1 might regulate the proliferation of NSCLC cells. To assess the effects of Ulk1 on cell proliferation, A549 and H460 cells were transfected with negative control (NC) or Ulk1-specific shRNA plasmids, and cell proliferation was measured by CCK8 assay. We found a significant decrease in the cell proliferation rate when Ulk1 was downregulated $(\mathrm{P}<0.01)$ (Fig. 2A and B). The EdU incorporation assay showed that the percentage of EdU-positive cells was obviously reduced when Ulk1 was downregulated (Fig. 2C). Taken together, the results suggest that knockdown of Ulk1 inhibits cell proliferation of NSCLC cells. 
A

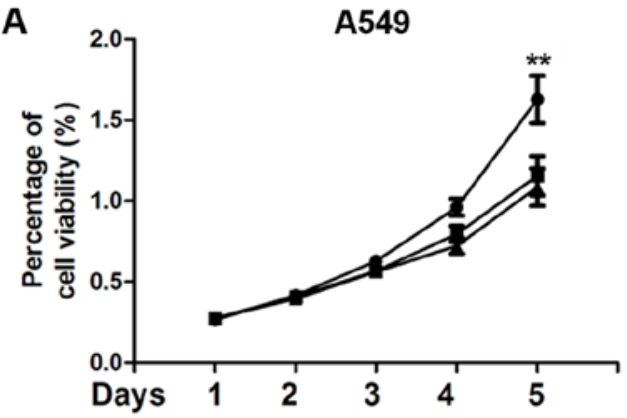

C
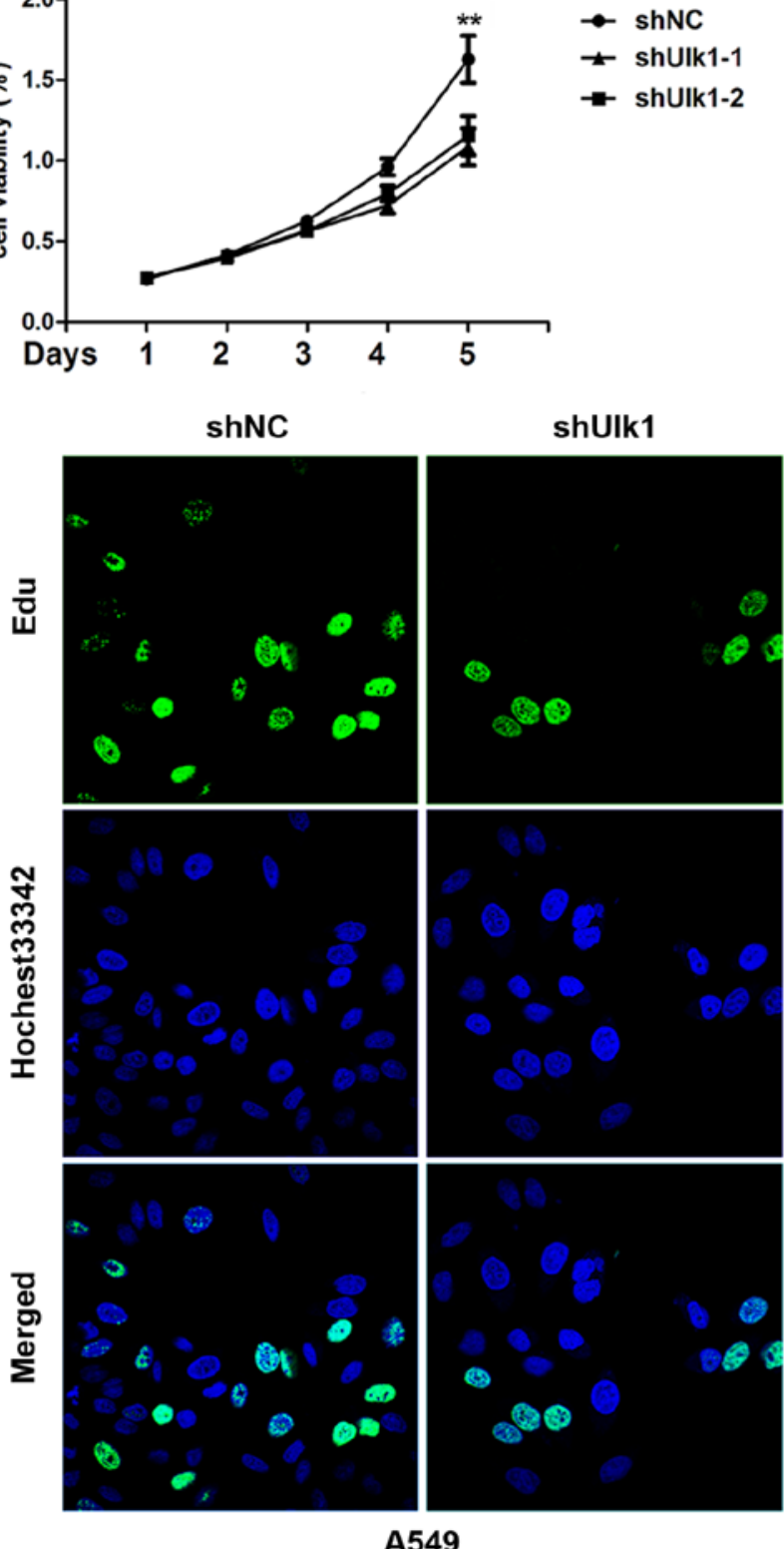

B

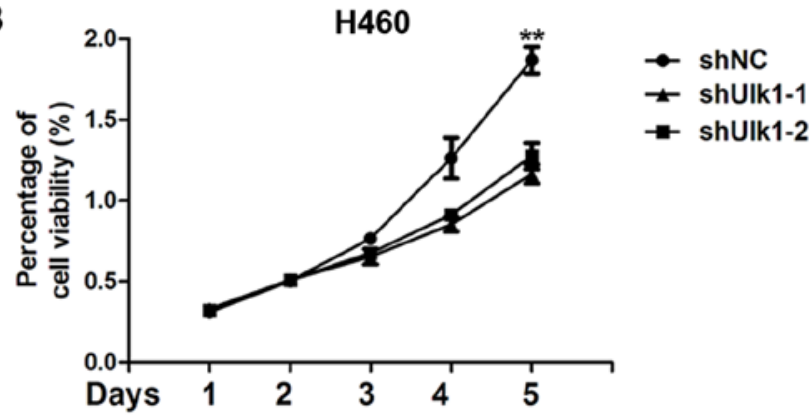

$\operatorname{shNC}$

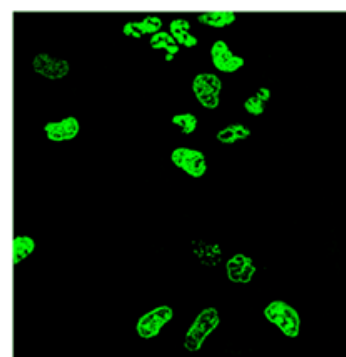

shUlk1
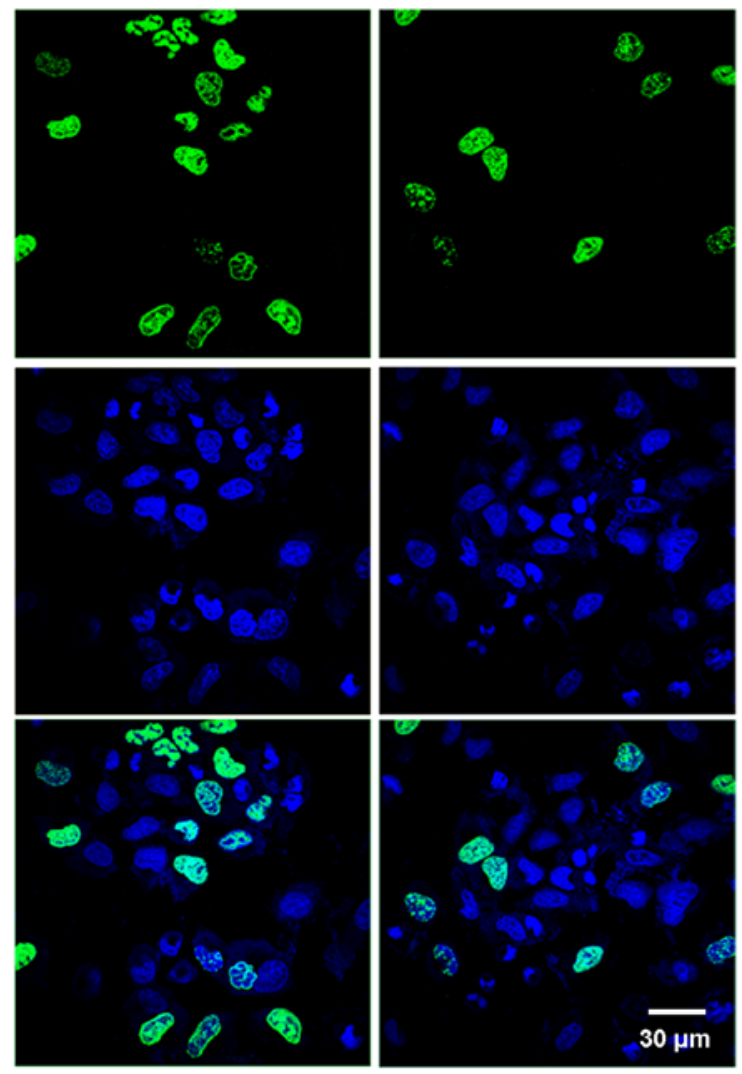

H460

Figure 2. Ulk1 promotes the proliferation of NSCLC cells. A549 (A) or H460 (B) cells were transfected with the indicated plasmids in quintuplicate and cell proliferation was monitored by CCK8 assay. (C) Cell proliferation was monitored by EdU incorporation assay after transfection. Scale bar, $30 \mu \mathrm{m}$. The results are representative data from three individual experiments. ${ }^{* *} \mathrm{P}<0.01, \mathrm{t}$-test.

Ulk1 confers resistance to cisplatin in NSCLC cells. Previous studies have shown that cisplatin upregulated both mRNA and protein levels of Ulk1 $(21,22)$. We speculated that cisplatin might have the same effects in Ulk1 in NSCLC cells. In this study, we found that cisplatin treatment upregulated the expression of mRNA and protein levels of Ulk1 in both A549 and H460 cells (Fig. 3A and B). Many NSCLC cells acquire resistance to the cytotoxicity induced by cisplatin, which limits the therapeutic efficacy of cisplatin. We wondered whether Ulk1 will contribute to resistance to cisplatin in NSCLC cells. To confirm this hypothesis, A549 and H460 cells transfected with NC or Ulk1-specific shRNA plasmids were exposed to cisplatin for $72 \mathrm{~h}$. As shown in Fig. 3D, and E, knockdown of
Ulk1 significantly impaired the viability of NSCLC cells after cisplatin treatment. Cisplatin causes apoptotic cell death in a dose-dependent manner (23). We therefore examined whether Ulk1 influences cisplatin-mediated apoptosis in NSCLC cells. As shown in Fig. 3C, knockdown of Ulk1 remarkably increased cisplatin-induced apoptosis. Moreover, knockdown of Ulk1 promoted apoptosis in the absence of stress. The results suggest that knockdown of Ulk1 can sensitize NSCLC cells to cisplatin.

Inhibition of Ulk1 kinase activity by SBI0206965 inhibits NSCLC cell proliferation and induces apoptosis of NSCLC cells. As described above, Ulk1 is associated with the 
A
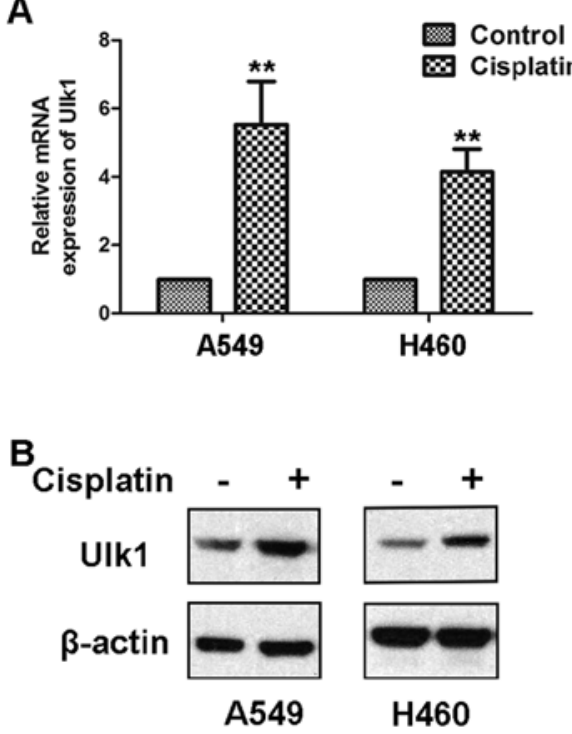

D

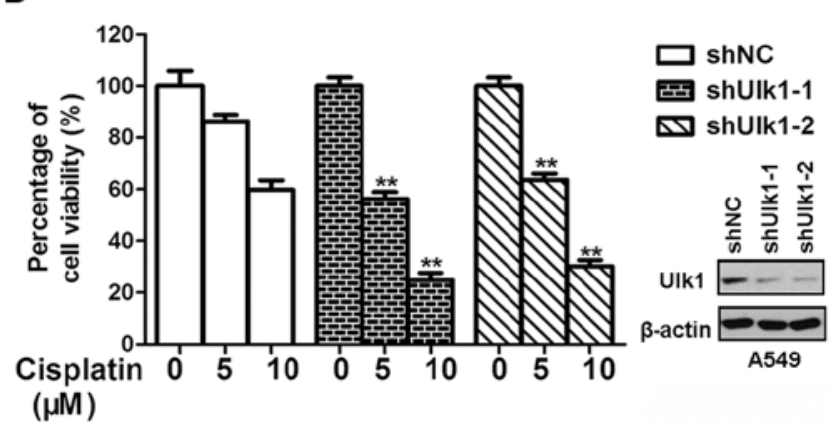

C
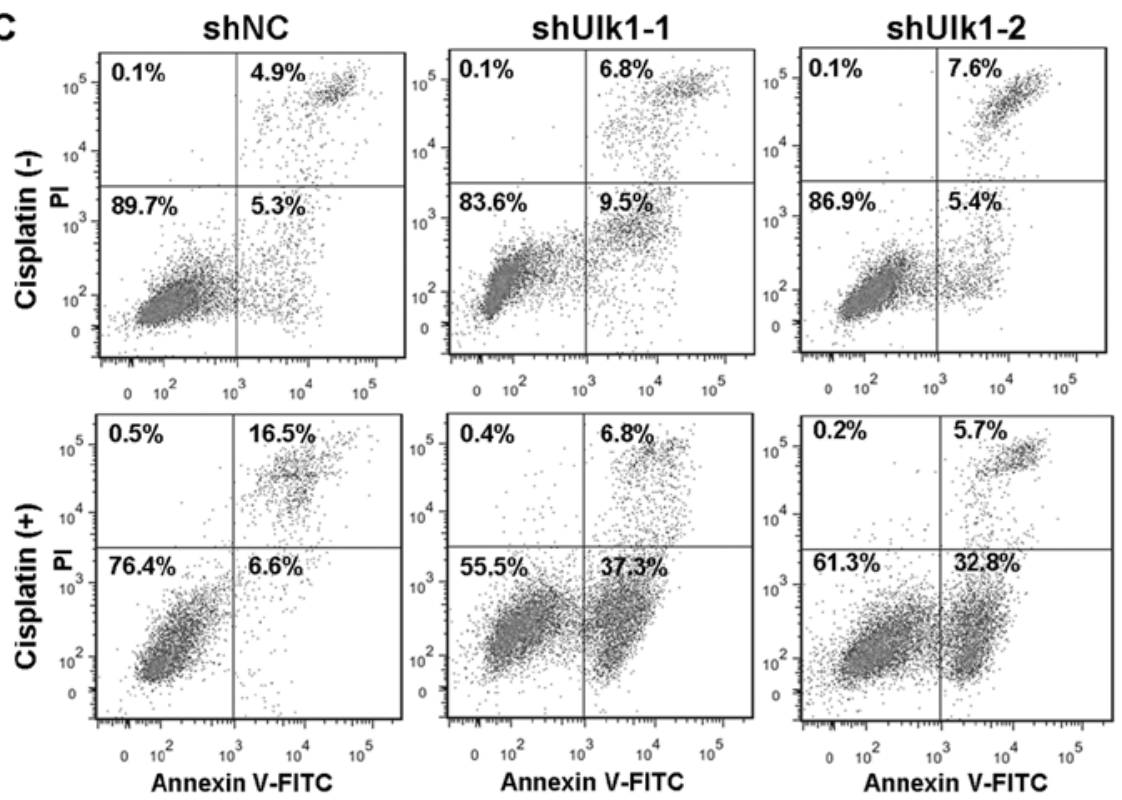

E

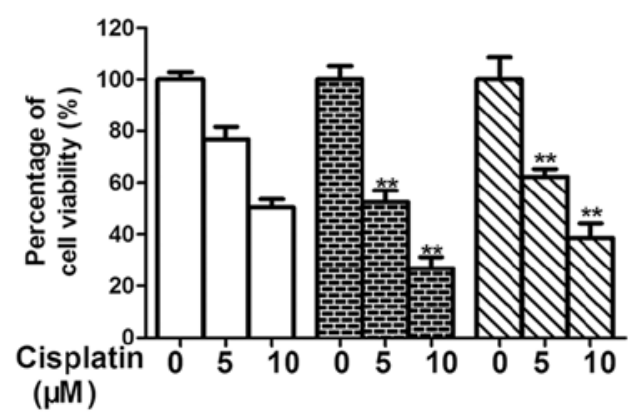

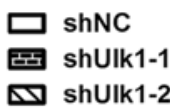

shUlk1-2

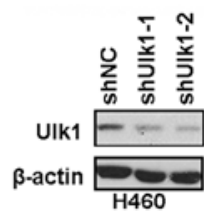
$(\mu \mathrm{M})$

Figure 3. Knockdown of Ulk1 sensitizes NSCLC cells to cisplatin-induced apoptosis and inhibition of cell proliferation. (A) The relative mRNA expression of Ulk1 after cisplatin treatment for $36 \mathrm{~h}$ in A549 and H460 cells. (B) Western blot analysis of changes in Ulk1 levels after cisplatin treatment for $48 \mathrm{~h}$ in A549 and H460 cells. (C) The percentages of apoptotic cells with Annexin V staining were determined by flow cytometry after transfection with the indicated shRNA plasmids for $48 \mathrm{~h}$ and treatment with the indicated concentrations of cisplatin for $48 \mathrm{~h}$. (D and E) The proliferation of A549 and H460 cells was determined by CCK8 assay after transfection and cisplatin treatment. ${ }^{* *} \mathrm{P}<0.01, \mathrm{t}$-test.

proliferation and apoptosis of NSCLC cells. Under stress conditions, Ulk1 is activated by AMPK-mediated phosphorylation and/or loss of the repression of mTOR (5). The autophagy cascade can be triggered when activated Ulk1 phosphorylates downstream targets $(10,11)$. Thus, the kinase activity of Ulk1 may play a vital role in autophagy-mediated survival in NSCLC cells under stress conditions. We used SBI0206965, a Ulk1-specific inhibitor, to confirm the role of Ulk1 (5). We first assessed the cytotoxicity of SBI0206965 in three human NSCLC cell lines: A549, H460 and HCC827. Inhibition of Ulk1 by SBI0206965 suppressed cell viability in a dose-dependent manner (Fig. 4A). The clonogenic survival assay revealed that the ability to form clones was decreased in SBI0206965 treatment groups, comparing with the control group (Fig. 4B). SBI0206965 treatment also induced apoptosis of NSCLC cells (Fig. 4C). Chemotherapy drugs generally kill cancer cells by inducing apoptosis (24). To clarify whether the role of SBI0206965 in apoptosis was responsible for the death of NSCLC cells, we introduced the pan caspase inhibitor Z-VAD-FMK into our study. The combination of inhibition of apoptosis by Z-VAD-FMK with
SBI0206965 remarkably improved cell viability compared with SBI0206965 alone (Fig. 4D and E). Taken together, the results suggest that inhibition of Ulk1 kinase activity by SBI0206965 impairs cell proliferation and induces apoptosis of NSCLC cells.

Inhibition of Ulk1 by SBI0206965 enhances the efficacy of cisplatin against NSCLC cells. Since knockdown of Ulk1 sensitized NSCLC cells to cisplatin, we speculated that the Ulk1 inhibitor SBI0206965 might enhance the efficacy of cisplatin against NSCLC. We therefore treated NSCLC cells with SBI0206965 and cisplatin either alone or in combination. In agreement with our hypothesis, targeting Ulk1 using SBI0206965 significantly impaired the viability of NSCLC cells after cisplatin treatment compared with cisplatin treatment without SBI0206965 (Fig. 5A and B). As shown in Fig. 5C, the percentage of Annexin V-positive cells was increased after co-treatment with SBI0206965 and cisplatin compared with SBI0206965 or cisplatin alone. Taken together, the results suggest that combination treatment with the Ulk1 inhibitor SBI0206965 and cisplatin enhanced cisplatin efficacy 

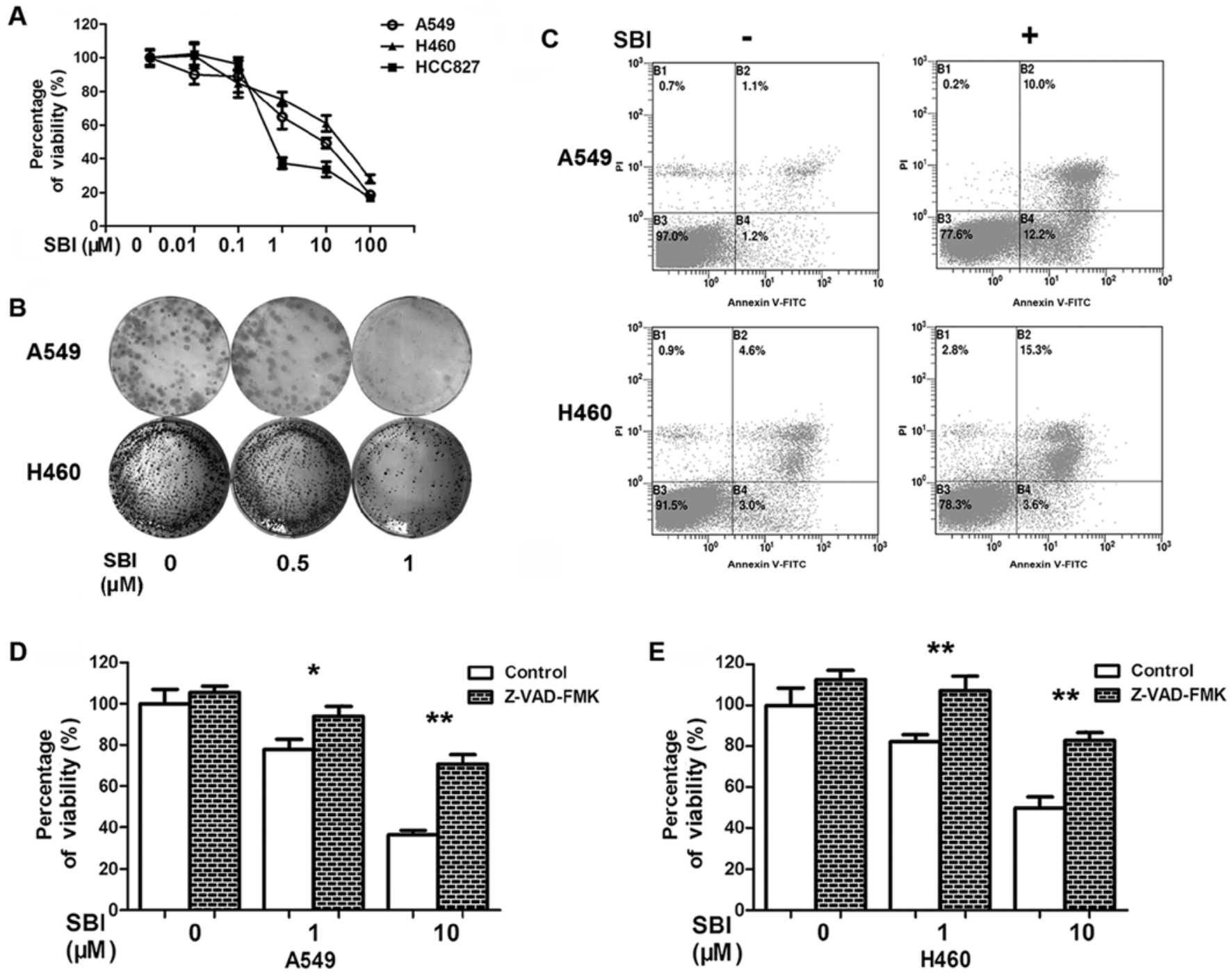

Figure 4. Inhibition of Ulk1 by SBI0206965 inhibits NSCLC cell growth and promotes apoptosis of NSCLC cells. (A) SBI0206965 impairs the viability of A549, H460 and HCC827 cells in a dose-dependent manner. Cells were treated with SBI0206965 in quintuplicate for $72 \mathrm{~h}$ and then assessed by CCK8 assay. (B) The growth of A549 and H460 cells was determined by clonogenic survival assay after treatment with the indicated doses of SBI0206965. The results are representatives of three individual experiments. (C) Apoptosis rates of A549 and H460 cells after treatment with SBI0206965. (D and E) SBI0206965mediated killing of NSCLC cells occurs via apoptosis. Cells were treated with SBI0206965 alone or co-treated with SBI0206965 and $20 \mu$ M Z-VAD-FMK, and cell viability was measured by CCK 8 assay. ${ }^{*} \mathrm{P}<0.05 ;{ }^{* *} \mathrm{P}<0.01$, t-test.

toward NSCLC cells, consistent with the results of treating Ulk1-knockdown cells with cisplatin.

SBI0206965 sensitizes NSCLC cells to cisplatin-induced apoptosis partly through autophagy inhibition. Next, we wanted to clarify the mechanism by which Ulk1 inhibition enhances cisplatin-induced death in NSCLC cells. Ulk1 is required for early autophagosome formation, as it forms a complex with ATG13 and RB1CC1 (10). Ulk1 also phosphorylates beclin1 and autophagy/beclin-1 regulator 1 (AMBRA1) to trigger the autophagy cascade $(25,26)$. Therefore, inhibition of Ulk1 should inhibit autophagy. As expected, SBI0206965 treatment inhibited autophagy, as evidenced by a reduction in LC3 I conversion to LC3 II, an increase in the levels of the autophagy substrate p62 and a decrease in GFP-LC3 dots (Fig. 6A and D). Many tumors become dependent on autophagy for survival and resistance to chemotherapeutic drugs, including cisplatin, by inhibiting apoptosis $(24,27)$.
Studies have shown that inhibition of autophagy sensitizes NSCLC cells to chemotherapy $(7,8)$. We confirmed that cisplatin induces autophagy in NSCLC cells (Fig. 6B and D). Co-treatment with SBI0206965 and cisplatin blocked the autophagy process induced by cisplatin (Fig. 6C and D). These results indicate that SBI0206965 enhanced the efficacy against cisplatin in NSCLC partly through inhibiting autophagy.

Inhibition of Ulk1 promotes apoptosis of NSCLC cells by destabilizing Bcl2 and Bclxl. In addition to its key roles in autophagy, Ulk1 has been shown to be involved in many signaling pathways that are closely correlated with tumorigenesis in NSCLC (5). Our preliminary experiment demonstrated that SBI0206965 can still inhibit cell proliferation and promote apoptosis when autophagy is inhibited by chloroquine (data not shown). We speculated that Ulk1 exerts oncogenic activity independent of autophagy. As mentioned above, inhibition of Ulk1 kinase activity by SBI0206965 
A

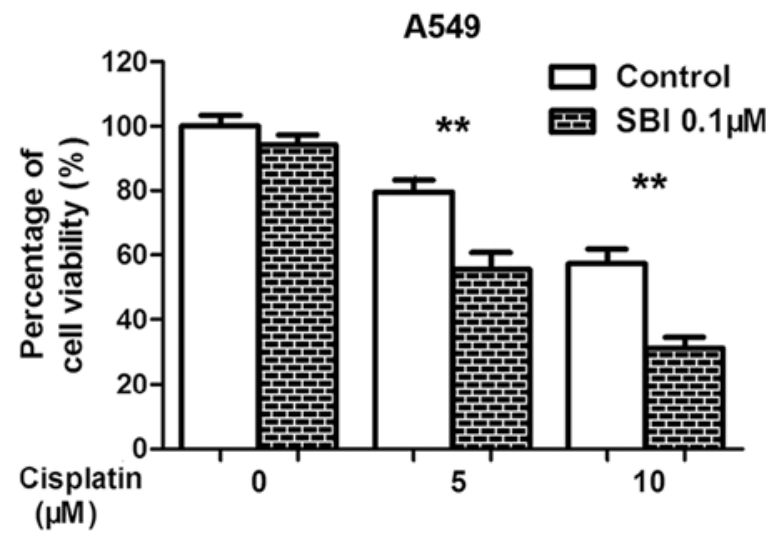

C
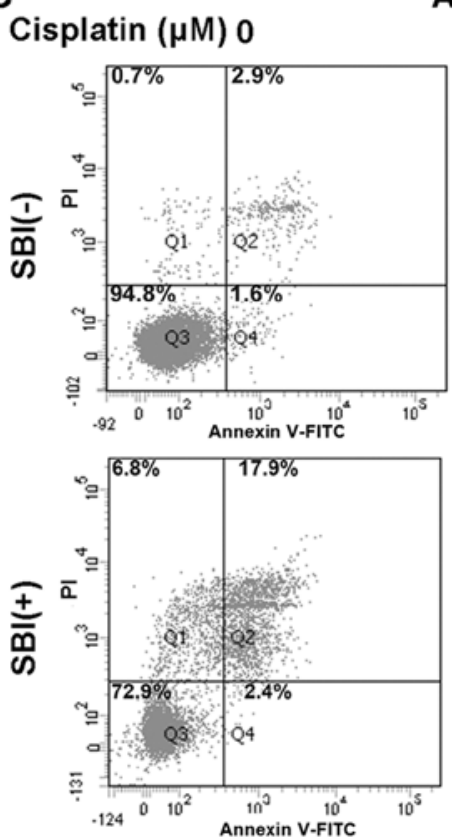

A549
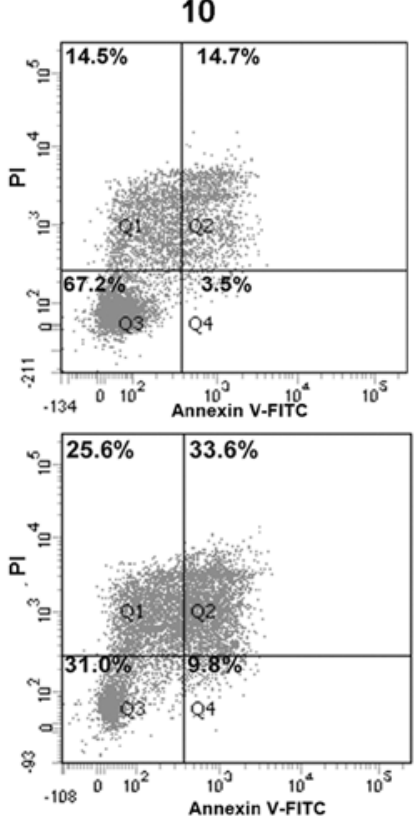

B

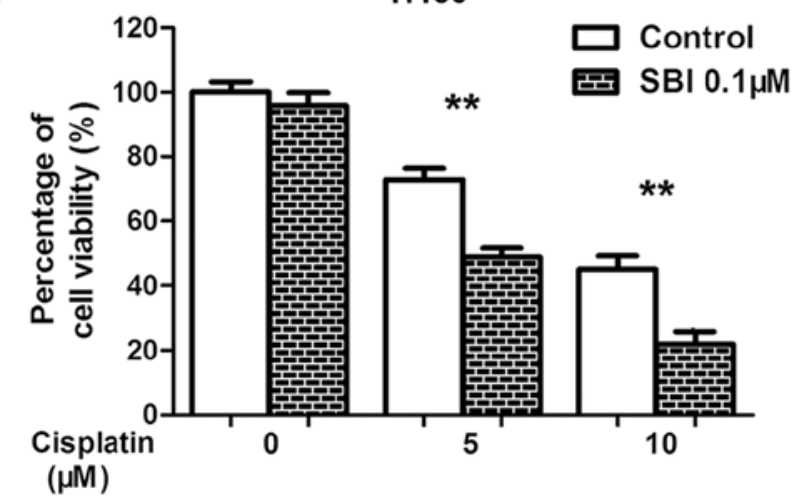

D

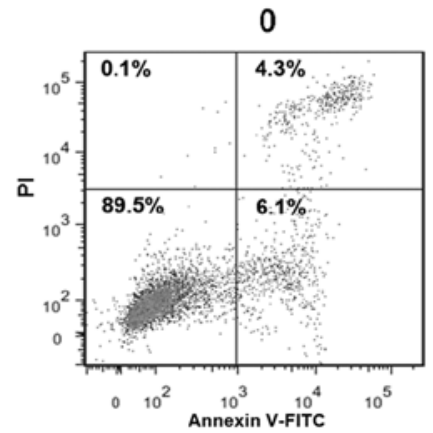

H460

Figure 5. SBI0206965 sensitizes NSCLC cells to cisplatin. (A and B) Viability of NSCLC cells after treating with the specified doses of cisplatin and SBI0206965 for $72 \mathrm{~h}$. (C and D) After $24 \mathrm{~h}$ of cisplatin and SBI0206965 exposure, the apoptosis of A549 and H460 cells was analyzed by flow cytometry as described in Materials and methods. ${ }^{* *} \mathrm{P}<0.01, \mathrm{t}$-test.

impairs cell proliferation mainly through induction of apoptosis. Thus, we focused on apoptosis-related proteins. We found that SBI0206965 treatment decreased Bcl2 and Bclxl protein levels in a dose-dependent manner (Fig. 7A). Moreover, knockdown of Ulk1 showed similar results (Fig. 7B). Furthermore, we performed qRT-PCR analysis to evaluate the mRNA levels of Bcl2 and Bclxl under SBI0206965 treatment. As shown in Fig. 7C and D, SBI0206965 had no obvious influence on the mRNA levels of Bcl2 and Bclxl compared with the control groups. The results indicated that the downregulation of Bcl2 and Bclxl by SBI0206965 treatment did not occur at the transcription level. Taken together, SBI0206965 can promote apoptosis of NSCLC cells independent of autophagy by destabilizing $\mathrm{Bcl} 2$ and $\mathrm{Bclxl}$.

\section{Discussion}

Lung cancer has become a major public health problem worldwide and seriously affects the quality of life of affected patients. Currently, most lung cancer patients are diagnosed when they already have advanced-stage disease, and the 5 -year survival rate for lung cancer is only $16.8 \%$ (28). Despite potentially curative resection treatment, recurrence and metastasis result in the death of nearly $40 \%$ of patients with NSCLC within 5 years (29). Therefore, further studies are required to discover and identify novel and specific biomarkers of NSCLC to benefit patient survival and quality of life.

Autophagy is a homeostatic and evolutionarily conserved process that degrades redundant or faulty cell components, and has an important role in maintaining intracellular homeostasis and survival under stressed conditions, such as energy deprivation (6). Autophagy is important in the normal development and cellular response to environmental stimuli. Dysregulated autophagy is emerging as a hallmark of malignancy (30). Karsli-Uzunbas et al showed that autophagy may be particularly relevant in lung cancer (4). Autophagy is a complex process that is divided into several phases 

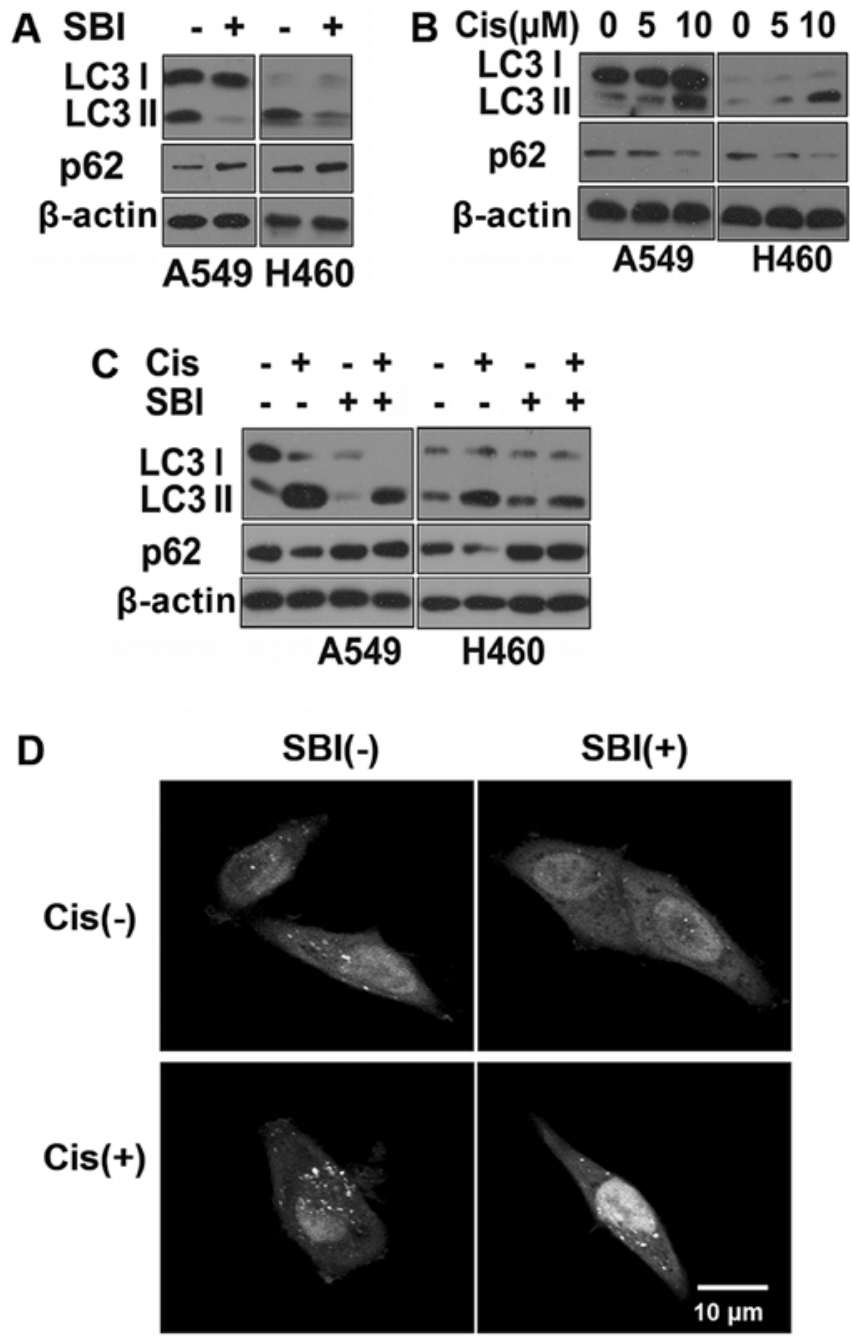

Figure 6. SBI0206965 sensitizes NSCLC cells to cisplatin partly through autophagy inhibition. (A-C) Western blot analysis of changes in LC3 I, LC3 II, and p62 levels after SBI0206965 and/or cisplatin treatment. (D) A549 cells were transfected with GFP-LC3 plasmids, and the cells were then treated with SBI0206965 and cisplatin either alone or in combination for $24 \mathrm{~h}$. GFPLC3 dots were observed by laser confocal microscopy. The presented results are representative of three independent experiments. Scale bars, $10 \mu \mathrm{m}$.

controlled by the autophagy-related (ATG) proteins. The role of autophagy and the function of many autophagy-related proteins in cancer have been extensively studied; for example, Beclin1, ATG5 or ATG7 knockout cell lines or mouse models have contributed greatly to the elucidation of autophagy in tumorigenesis $(31,32)$. Ulk1 plays a key role in the initial stages of autophagy (10), but the role of Ulk1 in cancer has remained largely unknown. Pike et al showed that Ulk1 is required for autophagy in severe hypoxia and that knockdown of Ulk1 causes cell death in a caspase-3/7-independent manner (12). Several other groups also showed that high expression of Ulk1 is associated with poor prognosis in breast cancer, colorectal cancer, esophageal squamous cell carcinoma and human nasopharyngeal carcinoma (12-15). However, studies have also shown that Ulk1 inhibits cell proliferation and induces apoptosis in other cancer cell types (33-36). It is clear that autophagy plays complex roles in tumorigenesis, progression and resistance to treatment that may be context specific (30). Therefore, the function of Ulk1 in tumorigenesis might be cancer type specific. Our study showed that Ulk1 was upregulated in NSCLC cells and was negatively correlated with prognosis in NSCLC, and that Ulk1 induced cell proliferation and inhibited apoptosis in NSCLC cells. Consistent with this, inhibition of Ulk1 by knockdown of Ulk1 or by treatment with SBI0206965, a novel Ulk1 inhibitor, impaired proliferation and induces cell apoptosis in NSCLC cells. Therefore, Ulk1 may contribute to tumorigenesis and progression in NSCLC.

Autophagy initiation involves the formation of a phagophore and Ulk1 functions as a facilitator of phagophore formation (37). Upon stress condition, activated AMP-activated protein kinase (AMPK) activates Ulk1, leading to the initiation of autophagy (11). ATG4 cleaved LC3 to generate the LC3 I form. Subsequently, LC3 I is activated by Atg7 catalyzing acyl adenylation of the $\mathrm{C}$ terminus, transferred to the E2-conjugating enzyme, Atg3, and modified to a membranebound form, LC3 II $(38,39)$. LC3 protein is associated with autophagosome development and maturation and is used to monitor autophagic activity. In this study, we found a reduction in LC3 I conversion to LC3 II, an increase in the level of the autophagy substrate p62 and a decrease in the number of GFP-LC3 dots after SBI0206965 treatment or knockdown of Ulk1. It is possible that Ulk1 promotes cell survival in NSCLC cells by inducing autophagy.

Previous studies showed an increase in the level of Ulk1 after cisplatin treatment $(21,22)$. In this study we found that cisplatin upregulated the expression of both mRNA and protein levels of Ulk1 in NSCLC cells. In addition to traditional surgical resection and radiotherapy, chemotherapy remains a common treatment for lung cancer. Many NSCLC cells acquire resistance to the cytotoxicity induced by cisplatin, which limits the therapeutic efficacy of cisplatin. Previous studies have demonstrated that cell-protective autophagy confers resistance to cisplatin in lung cancer cells $(23,27)$. Cisplatin causes apoptotic cell death in a dose-dependent manner (23). Autophagy can promote cell survival under stress conditions by suppressing apoptosis (24). In this study, we found that cisplatin treatment induced autophagy, and that knockdown of Ulk1 or inhibition of Ulk1 by SBI0206965 significantly impaired the viability of NSCLC cells and increased the apoptotic cells with cisplatin treatment. The results indicated that Ulk1 may confer resistance to cisplatin, and that SBI0206965 may increase the sensitivity of cisplatin against NSCLC cells by autophagy inhibition. These results showed an association between Ulk1 and cisplatin resistance, and may provide a strong rationale for the combined use of SBI0206965 and cisplatin in the clinic.

Another important phenomenon we observed was that knockdown of Ulk1 or treatment with SBI0206965 decreased two apoptosis-related proteins: Bcl2 and Bclxl, in NSCLC cells, without obvious influence on the transcription levels of Bcl2 and Bclxl. Ulk1 has been shown to be involved in many signaling pathways that are closely correlated with tumorigenesis (5). Apoptosis and autophagy are both closely regulated biological processes in cancer cells (40). Impaired apoptosis is both critical in cancer development and a major barrier to effective treatment (41). The $\mathrm{Bcl} 2$ family proteins play complex roles in cell apoptosis and survival signaling (40,42-44). Bcl2 and Bclxl are often overexpressed in NSCLC, conferring resistance to chemotherapy and exerting 

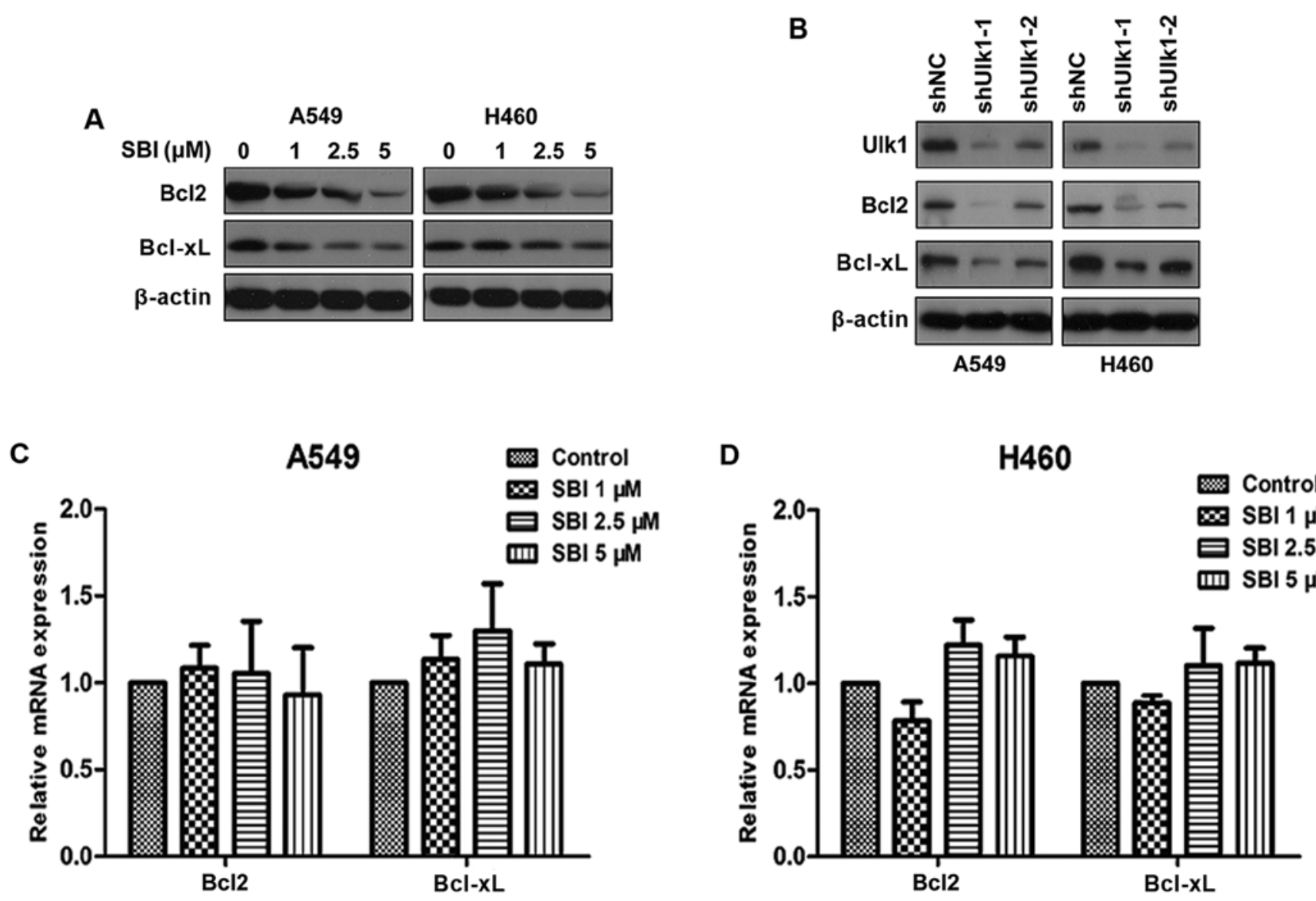

Figure 7. SBI0206965 destabilizes Bc12/Bclxl. (A and B) Representative immunoblots of Bcl2 levels and Bclxl levels in A549 and H460 cells after treatment with the indicated doses of SBI0206965 (A) or transfection with the indicated plasmids (B) for $72 \mathrm{~h}$. (C and D) The relative mRNA expression of Bcl2 and Bclxl after SBI0206965 treatment for $36 \mathrm{~h}$ in A549 and H460 cells.

anti-apoptotic functions in response to a wide range of apoptotic stimuli (45). Downregulation of $\mathrm{Bcl} 2$ and $\mathrm{Bclxl}$ restores cisplatin sensitivity (46). It is possible that the inhibition of Ulk1 may suppress NSCLC cell growth and increase the sensitivity of cisplatin in NSCLC cells by apoptosis pathway.

There are five Ulk1 homologs in the human genome: Ulk1, Ulk2, Ulk3, Ulk4, and serine/threonine kinase 36 (STK36) (47). However, only Ulk1 and Ulk2 are known to have roles in regulating autophagy, and Ulk2 also has distinct functions. It should be noted that this study examined only the function of Ulk1 in NSCLC cells, and whether Ulk2 or other Ulk1 homologs have the same functions as Ulk1 in lung cancer cells requires further study. In addition, our results lack the underlying mechanisms to explain how Ulk1 influences the protein levels of $\mathrm{Bcl} 2$ and $\mathrm{Bclxl}$, which needs further investigation.

In summary, we report that SBI0206965, an inhibitor of Ulk1, exerts anti-tumor effects in NSCLC. Moreover, the effects of SBI0206965 occur in both autophagy-dependent and autophagy-independent manner. Therefore, Ulk1 might be a potential target for treating NSCLC and reversing cisplatin resistance.

\section{Acknowledgements}

This study was supported by grants from the National Natural Sciences Foundation of Hubei Province (no. 2013CFA006).

\section{References}

1. Torre LA, Bray F, Siegel RL, Ferlay J, Lortet-Tieulent J and Jemal A: Global cancer statistics, 2012. CA Cancer J Clin 65: 87-108, 2015.

2. Politi $\mathrm{K}$ and Herbst RS: Lung cancer in the era of precision medicine. Clin Cancer Res 21: 2213-2220, 2015.

3. Rubinsztein DC, Gestwicki JE, Murphy LO and Klionsky DJ: Potential therapeutic applications of autophagy. Nat Rev Drug Discov 6: 304-312, 2007.

4. Karsli-Uzunbas G, Guo JY, Price S, Teng X, Laddha SV, Khor S, Kalaany NY, Jacks T, Chan CS, Rabinowitz JD, et al: Autophagy is required for glucose homeostasis and lung tumor maintenance. Cancer Discov 4: 914-927, 2014.

5. Egan DF, Chun MG, Vamos M, Zou H, Rong J, Miller CJ, Lou HJ, Raveendra-Panickar D, Yang CC, Sheffler DJ, et al: Small molecule inhibition of the autophagy kinase ULK1 and identification of ULK1 substrates. Mol Cell 59: 285-297, 2015.

6. Guo JY, Xia B and White E: Autophagy-mediated tumor promotion. Cell 155: 1216-1219, 2013.

7. Fung C, Chen X, Grandis JR and Duvvuri U: EGFR tyrosine kinase inhibition induces autophagy in cancer cells. Cancer Biol Ther 13: 1417-1424, 2012.

8. Li X, Lu Y, Pan T and Fan Z: Roles of autophagy in cetuximabmediated cancer therapy against EGFR. Autophagy 6: 1066-1077, 2010.

9. Chan EY, Kir S and Tooze SA: siRNA screening of the kinome identifies ULK1 as a multidomain modulator of autophagy. J Biol Chem 282: 25464-25474, 2007.

10. Ganley IG, Lam H, Wang J, Ding X, Chen S and Jiang X: ULK1. ATG13.FIP200 complex mediates mTOR signaling and is essential for autophagy. J Biol Chem 284: 12297-12305, 2009.

11. Liu CC, Lin YC, Chen YH, Chen CM, Pang LY, Chen HA, Wu PR, Lin MY, Jiang ST, Tsai TF, et al: Cul3-KLHL20 ubiquitin ligase governs the turnover of ULK1 and VPS34 complexes to control autophagy termination. Mol Cell 61: 84-97, 2016. 
12. Pike LR, Singleton DC, Buffa F, Abramczyk O, Phadwal K, Li JL, Simon AK, Murray JT and Harris AL: Transcriptional up-regulation of ULK1 by ATF4 contributes to cancer cell survival. Biochem J 449: 389-400, 2013.

13. Yun M, Bai HY, Zhang JX, Rong J, Weng HW, Zheng ZS, $\mathrm{Xu}$ Y, Tong ZT, Huang XX, Liao YJ, et al: ULK1: A promising biomarker in predicting poor prognosis and therapeutic response in human nasopharygeal carcinoma. PLoS One 10: e0117375, 2015.

14. Tang J, Deng R, Luo RZ, Shen GP, Cai MY, Du ZM, Jiang S, Yang MT, Fu JH and Zhu XF: Low expression of ULK1 is associated with operable breast cancer progression and is an adverse prognostic marker of survival for patients. Breast Cancer Res Treat 134: 549-560, 2012.

15. Zou Y, Chen Z, He X, He X, Wu X, Chen Y, Wu X, Wang J and Lan P: High expression levels of unc-51-like kinase 1 as a predictor of poor prognosis in colorectal cancer. Oncol Lett 10: $1583-1588,2015$

16. Jiang S, Li Y, Zhu YH, Wu XQ, Tang J, Li Z, Feng GK, Deng R, $\mathrm{Li}$ DD, Luo RZ, et al: Intensive expression of UNC-51-like kinase 1 is a novel biomarker of poor prognosis in patients with esophageal squamous cell carcinoma. Cancer Sci 102: 1568-1575, 2011.

17. Stewart SA, Dykxhoorn DM, Palliser D, Mizuno H, Yu EY, An DS, Sabatini DM, Chen IS, Hahn WC, Sharp PA, et al: Lentivirus-delivered stable gene silencing by RNAi in primary cells. RNA 9: 493-501, 2003

18. Fung C, Lock R, Gao S, Salas E and Debnath J: Induction of autophagy during extracellular matrix detachment promotes cell survival. Mol Biol Cell 19: 797-806, 2008.

19. Győrffy B, Surowiak P, Budczies J and Lánczky A: Online survival analysis software to assess the prognostic value of biomarkers using transcriptomic data in non-small-cell lung cancer. PLoS One 8: e82241, 2013.

20. Sakuma Y, Yamazaki Y, Nakamura Y, Yoshihara M, Matsukuma S, Nakayama H, Yokose T, Kameda Y, Koizume S and Miyagi Y: WZ4002, a third-generation EGFR inhibitor can overcome anoikis resistance in EGFR-mutant lung adenocarcinomas more efficiently than Src inhibitors. Lab Invest 92 371-383, 2012

21. Shen M, Duan WM, Wu MY, Wang WJ, Liu L, Xu MD, Zhu J, Li DM, Gui Q, Lian L, et al: Participation of autophagy in the cytotoxicity against breast cancer cells by cisplatin. Oncol Rep 34: 359-367, 2015

22. Huang Y, Guerrero-Preston R and Ratovitski EA: Phospho$\Delta \mathrm{Np} 63 \alpha$-dependent regulation of autophagic signaling through transcription and micro-RNA modulation. Cell Cycle 11: 1247-1259, 2012

23. Ren JH, He WS, Nong L, Zhu QY, Hu K, Zhang RG, Huang LL, Zhu F and Wu G: Acquired cisplatin resistance in human lung adenocarcinoma cells is associated with enhanced autophagy. Cancer Biother Radiopharm 25: 75-80, 2010.

24. Sui X, Chen R, Wang Z, Huang Z, Kong N, Zhang M, Han W, Lou F, Yang J, Zhang Q, et al: Autophagy and chemotherapy resistance: A promising therapeutic target for cancer treatment. Cell Death Dis 4: e838, 2013.

25. Russell RC, Tian Y, Yuan H, Park HW, Chang YY, Kim J, Kim H, Neufeld TP, Dillin A and Guan KL: ULK1 induces autophagy by phosphorylating Beclin-1 and activating VPS34 lipid kinase. Nat Cell Biol 15: 741-750, 2013.

26. Di Bartolomeo S, Corazzari M, Nazio F, Oliverio S, Lisi G, Antonioli M, Pagliarini V, Matteoni S, Fuoco C, Giunta L, et al: The dynamic interaction of AMBRA1 with the dynein motor complex regulates mammalian autophagy. J Cell Biol 191: $155-168,2010$

27. Liu JT, Li WC, Gao S, Wang F, Li XQ, Yu HQ, Fan LL, Wei W, Wang $H$ and Sun GP: Autophagy inhibition overcomes the antagonistic effect between gefitinib and cisplatin in epidermal growth factor receptor mutant non-small-cell lung cancer cells. Clin Lung Cancer 16: e55-e66, 2015.
28. Ettinger DS, Wood DE, Akerley W, Bazhenova LA, Borghaei H, Camidge DR, Cheney RT, Chirieac LR, D'Amico TA, Demmy TL, et al; National comprehensive cancer network: Non-small cell lung cancer, version 6.2015. J Natl Compr Canc Netw 13: 515-524, 2015 .

29. Reck M,Heigener DF, Mok T, Soria JC and Rabe KF: Management of non-small-cell lung cancer: Recent developments. Lancet 382: 709-719, 2013.

30. White E: Deconvoluting the context-dependent role for autophagy in cancer. Nat Rev Cancer 12: 401-410, 2012.

31. Rao S, Tortola L, Perlot T, Wirnsberger G, Novatchkova M, Nitsch R, Sykacek P, Frank L, Schramek D, Komnenovic V, et al: A dual role for autophagy in a murine model of lung cancer. Nat Commun 5: 3056, 2014.

32. Strohecker AM, Guo JY, Karsli-Uzunbas G, Price SM, Chen GJ, Mathew R, McMahon M and White E: Autophagy sustains mitochondrial glutamine metabolism and growth of BrafV600Edriven lung tumors. Cancer Discov 3: 1272-1285, 2013.

33. Joshi A, Iyengar R, Joo JH, Li-Harms XJ, Wright C, Marino R, Winborn BJ, Phillips A, Temirov J, Sciarretta S, et al: Nuclear ULK1 promotes cell death in response to oxidative stress through PARP1. Cell Death Differ 23: 216-230, 2016.

34. Jung CH, Seo M, Otto NM and Kim DH: ULK1 inhibits the kinase activity of mTORC1 and cell proliferation. Autophagy 7 : 1212-1221, 2011

35. Gao W, Shen Z, Shang L and Wang X: Upregulation of human autophagy-initiation kinase ULK1 by tumor suppressor p53 contributes to DNA-damage-induced cell death. Cell Death Differ 18: 1598-1607, 2011.

36. Mukhopadhyay S, Das DN, Panda PK, Sinha N, Naik PP, Bissoyi A, Pramanik K and Bhutia SK: Autophagy protein Ulk1 promotes mitochondrial apoptosis through reactive oxygen species. Free Radic Biol Med 89: 311-321, 2015.

37. Schaaf MB, Keulers TG, Vooijs MA and Rouschop KM: LC3/ GABARAP family proteins: Autophagy-(un)related functions. FASEB J 30: 3961-3978, 2016.

38. Tanida I, Ueno T and Kominami E: LC3 conjugation system in mammalian autophagy. Int J Biochem Cell Biol 36: 2503-2518, 2004.

39. Tanida I, Tanida-Miyake E, Ueno $\mathrm{T}$ and Kominami E: The human homolog of Saccharomyces cerevisiae Apg7p is a Protein-activating enzyme for multiple substrates including human Apg12p, GATE-16, GABARAP, and MAP-LC3. J Biol Chem 276: 1701-1706, 2001.

40. Rikiishi H: Novel insights into the interplay between apoptosis and autophagy. Int J Cell Biol 2012: 317645, 2012.

41. Adams JM and Cory S: The Bcl-2 apoptotic switch in cancer development and therapy. Oncogene 26: 1324-1337, 2007.

42. Strasser A and Bouillet P: The control of apoptosis in lymphocyte selection. Immunol Rev 193: 82-92, 2003.

43. Cory S and Adams JM: The Bcl2 family: Regulators of the cellular life-or-death switch. Nat Rev Cancer 2: 647-656, 2002.

44. Gil J, Ramsey D, Szmida E, Leszczynski P, Pawlowski P, Bebenek M and Sasiadek MM: The BAX gene as a candidate for negative autophagy-related genes regulator on mRNA levels in colorectal cancer. Med Oncol 34: 16, 2017.

45. Park D, Magis AT, Li R, Owonikoko TK, Sica GL, Sun SY, Ramalingam SS, Khuri FR, Curran WJ and Deng X: Novel small-molecule inhibitors of Bcl-XL to treat lung cancer. Cancer Res 73: 5485-5496, 2013.

46. Wangpaichitr M, Wu C, You M, Kuo MT, Feun L, Lampidis T and Savaraj N: Inhibition of mTOR restores cisplatin sensitivity through down-regulation of growth and anti-apoptotic proteins. Eur J Pharmacol 591: 124-127, 2008.

47. Ro SH, Jung CH, Hahn WS, Xu X, Kim YM, Yun YS, Park JM, $\mathrm{Kim} \mathrm{KH}$, Seo M, Ha TY, et al: Distinct functions of Ulk1 and Ulk2 in the regulation of lipid metabolism in adipocytes. Autophagy 9: 2103-2114, 2013. 